\title{
MATHEMATICAL MODEL OF HYDRAULIC SYSTEMS AND APPLICATION TO IRRIGATION PROBLEMS
}

\begin{abstract}
Asaf Hajiyev, Y. Rustamov
Azerbaijan National Academy of Sciences, Institute of Control Systems, Azerbaijan

Received - April 29, 2017; Revision - May 21, 2017; Accepted - June 18, 2017

Available Online - August 31, 2017

DOI: http://dx.doi.org/10.18006/2017.5(Spl-1-SAFSAW).S108.S115

\section{KEYWORDS}

Pumping Station

Reliability

Goodness Fit Criterion

Structural Design

\section{ABSTRACT}

In this paper, a mathematical model of pumping systems has been constructed. The model is important in calculating the probability distribution of operation system failures. Using the constructed mathematical model and also statistical data of the some actual systems in district Salyan, Azerbaijan, the probability distribution of operation system failures was determined. In this connection, a software has been developed for applications in practical problems. The suggested model is universal and can be used in the different regions including the Arab World.
\end{abstract}

Weibull Distribution
* Corresponding author

E-mail: asaf.hajiyev@gmail.com (Asaf Hajiyev)

Peer review under responsibility of Journal of Experimental Biology and Agricultural Sciences.

Production and Hosting by Horizon Publisher India [HPI] (http://www.horizonpublisherindia.in/).

All rights reserved.
All the article published by Journal of Experimental Biology and Agricultural Sciences is licensed under a Creative Commons Attribution-NonCommercial 4.0 International License Based on a work at www.jebas.org.

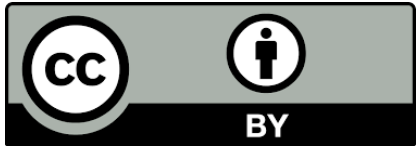




\section{Introduction}

Scarcity of water resources is a worldwide dilemma including the countries in Africa, Asia, and the Arab World and to some extent in Europe. Optimal use of these systems is of basic importance and improvement in these systems can reduce the water scarcity problems to some extent. In this regard, pumping stations are the main players, their improved construction and optimal operation in addition to effective functioning of irrigation system is of central standing. Optimal functioning of such systems plays an important role in economics, as well as in people's daily lives. Estimation of operating reliability of these systems allows effectively organizing functioning of pumping, collector-drainage and other irrigation systems. In, various methods for estimating the reliability of complicated systems are described (Belyaev, 1976; Barlou \&, Proshan, 1984; Hajiyev \& Shahbazov, 2000; Gnedenko et al., 2013). Although the above mentioned methods are general, it is difficult to apply them directly to concrete practical problems. Hence, for each particular case, it is necessary to create special universal model. Lower reliability of a pumping stations can leads to increased operating costs of such systems and reduce service life and economical efficiency. Additionally, inefficient pumping stations lead to substantial material and financial losses (Ahmedzade \& Hashimov, 2016; Rustamov, 2010; Rustamov, 2013).

Failures of a pumping station during operation are a random sequence. In order to evaluate non-failure operation of a pumping station, it is necessary to estimate the reliability of the system, which has a probabilistic structure.

The reliability of pumping station involves several main parameters, such as non-failure operation probability $(\mathrm{P}(t))$ and an average operation time $\left(T_{0}\right)$. The availability factor $\left(K_{h}\right)$ and the operation periods $(T)$ between failures, have a complicated structure (Polovko \& Gurov, 2008; State Standards, 1990). According to normative requirements, for evaluation of the reliability of restored equipment, it is necessary to calculate $K_{h}$ and $T_{0}$, which are defined in Polovko \& Gurov (2008).

This paper suggests a new method of estimating the non-failure operation (Ahmadova et al., 2010) for various irrigation systems. Using statistical data of a working pumping station, it is shown that for some applications, the probability distribution of continuous operation of a system can be effectively approximated by Weibull distribution.

\section{Problem statement}

A pumping station Shimal-2 of district Salyan, Azerbaijan consisting several $n$ pumping units was considered for this task. Table 1 shows the operating hours of the pumping station over a one-year time period. For simplicity, we put $n=3$, although the method can be generalized for any $n$. Using statistical data of the pumping station a probability distribution of operation system failures was estimated. Below is given the table with data from pumping station Shimal-2.

Some results from hypothesis theory (Lehmann,1959) will be used in testing of a distribution of operation system failure. In the capacity of a zero hypothesis, it was assumed that variation series $\left(t_{1} \prec t_{2} \prec \ldots \prec t_{r}\right) \delta=0$ for operating hours of pumping units corresponds to the two-parameter Weibull distribution. If the zero hypotheses are rejected, other distributions including threeparameter Weibull distribution can be considered. There are various approaches to estimate the reliability of a functioning system (Hajiyev \& Shahbazov, 2000), however, some authors have only used the goodness fit criterion, prepared for Weibull distribution (Mann et al., 1971; Kapur \& Lamberson,1980).

\section{Problem solution}

By goodness fit criterion we have $S_{m} \approx 0,29$.

The calculations show that for accuracy level $r=10$ and $\alpha=0,05$.The critical value of the criterion $S_{b}=0,69$. As $S_{m} \prec S_{b}$, for this case, the operating hours between failures corresponds to two-parameter Weibull distribution, which has the following form

$$
F(x ; a, b)=1-e^{-\left(\frac{t}{a}\right)^{b}} \quad x \geq 0
$$

Here $a$ is the scale or resource parameter, and $b$ is the shape parameter or angular coefficient.

Using the substitution, $x=\ln t$, for distribution function of the random variable $\mathrm{x}$, we have

$$
F(x)=1-\exp \left[-\exp \left(\frac{x-u}{V}\right)\right],(-\infty \prec x \prec \infty)
$$

\begin{tabular}{|c|c|c|c|c|c|c|c|c|c|c|c|c|}
\hline \multirow{2}{*}{$\begin{array}{c}\text { № of } \\
\text { PU }\end{array}$} & \multicolumn{11}{|c|}{ Months } & \multirow{2}{*}{$\begin{array}{l}\text { Type of the } \\
\text { pump }\end{array}$} \\
\hline & I & II & III & IV & V & VI & VII & VIII & IX & $X$ & XI & \\
\hline 1 & 248 & 252 & 351 & 450 & 480 & 440 & 445 & 362 & 390 & 415 & - & $16 \mathrm{NDN}$ \\
\hline 2 & 350 & 357 & 463 & 514 & 512 & 521 & 585 & 396 & 275 & 312 & 425 & $16 \mathrm{NDN}$ \\
\hline 3 & 196 & 340 & 270 & 310 & 335 & 364 & 200 & 273 & 445 & 300 & 285 & $24 \mathrm{NDN}$ \\
\hline
\end{tabular}

Table 1 Actual operating hours of Shimal-2 pumping station over a one-year time period 
Table 2 Actual operating hours of the first pumping unit

\begin{tabular}{|cccccc|}
\hline$i$ & $t_{i}$ & $X_{i}=\operatorname{lnt}_{i}$ & $M_{i}$ & $X_{i+1}-X_{i}$ & $\left(X_{i+1}-X_{i}\right) / M_{i}$ \\
\hline 1 & 248 & 5,5134 & 1,054 & 0,016 & 0,0152 \\
\hline 2 & 252 & 5,5294 & 0,559 & 0,3314 & 0,5928 \\
\hline 3 & 351 & 5,8608 & 0,399 & 0,0308 & 0,2292 \\
\hline 4 & 562 & 0,8916 & 0,325 & 0,0745 & 0,2175 \\
\hline 5 & 390 & 5,9661 & 0,286 & 0,0622 & 0,2175 \\
\hline 6 & 415 & 6,0283 & 0,269 & 0,0585 & 0,0113 \\
\hline 7 & 440 & 6,0868 & 0,271 & 0,0111 & 0,0369 \\
\hline 8 & 445 & 6,0981 & 0,301 & 0,0646 & 0,1595 \\
\hline 10 & 450 & 6,1092 & 0,405 & & 0 \\
\hline
\end{tabular}

110

(2) where $u=\ln a$ and $v=\frac{1}{b}$. If the reliability $(P)$ of the (3), we have equipment is known, for finding the random variable $\mathrm{x}$, we can rewrite expression (2) in the following form

$$
x=u+v\left[\ln \left(\ln \frac{1}{P}\right)\right]
$$

Linear weighted sets found for $r=10$ are given in Table 3.

Using the substitution $x_{i}=\ln t_{i}$ for the coefficients in expression

$$
\begin{aligned}
& \bar{u}=\sum_{i=1}^{r} a_{i} \cdot x_{i}, \\
& \bar{V}=\sum_{i=1}^{r} c_{i} \cdot x_{i} .
\end{aligned}
$$

Here $a_{i}$ and $c_{i}$ are linear weighted multipliers. Initial parameters and reliability for the case of Weibull distribution are calculated as

Table 3 Linear weighted sets

\begin{tabular}{|cccc|}
\hline$t_{i}$ & $\boldsymbol{X}_{i}=\operatorname{lnt}_{i}$ & $\boldsymbol{A}_{i}$ & $C_{i}$ \\
\hline 248 & 5,5134 & 0,0273 & $-0,07273$ \\
\hline 252 & 5,5294 & 0,0400 & $-0,07797$ \\
\hline 351 & 5,8608 & 0,0525 & $-0,07724$ \\
\hline 362 & 5,8916 & 0,0654 & $-0,07188$ \\
\hline 390 & 5,9661 & 0,0793 & $-0,06165$ \\
\hline 415 & 6,0283 & 0,0946 & $-0,04542$ \\
\hline 440 & 6,0868 & 0,0946 & $-0,02070$ \\
\hline 445 & 6,0981 & 0,1124 & 0,01793 \\
\hline 450 & 6,1092 & 0,1342 & 0,08507 \\
\hline 480 & 6,1738 & 0,2300 & 0,32460 \\
\hline
\end{tabular}

Journal of Experimental Biology and Agriculture Science http://www.jebas.org 
Table 4 Actual operating hours of the second pumping unit

\begin{tabular}{|llllll|}
\hline$i$ & $t_{i}$ & $X_{i}=l n t_{i}$ & $M_{i}$ & $X_{i+1}-X_{i}$ & $\left(X_{i+1}-X_{i}\right) / M_{i}$ \\
\hline 1 & 275 & 5,6168 & 1,0484 & 0,1262 & 0,1204 \\
\hline 2 & 312 & 5,7430 & 0,5528 & 0,1141 & 0,2064 \\
\hline 3 & 350 & 5,8579 & 0,3914 & 0,0198 & 0,0506 \\
\hline 4 & 357 & 5,8777 & 0,3147 & 0,1037 & 0,3295 \\
\hline 5 & 396 & 5,9814 & 0,2732 & 0,0707 & 0,3405 \\
\hline 6 & 425 & 6,0521 & 0,2514 & 0,0856 & 0,4125 \\
\hline 7 & 463 & 6,1377 & 0,2439 & 0,1006 & 0,0155 \\
\hline 8 & 512 & 6,2383 & 0,2515 & 0,0039 & 0,0539 \\
\hline 9 & 514 & 6,2422 & 0,2839 & 0,0153 & 0,2859 \\
\hline 10 & 521 & 6,2575 & 0,3891 & 0,1141 & \\
\hline 11 & 585 & 6,3716 & & & \\
\hline
\end{tabular}

$$
\begin{aligned}
& \bar{a}=e^{\bar{u}}, \\
& \bar{b}=\frac{1}{\bar{v}},
\end{aligned}
$$

(7)

$$
\bar{P}(t)=\exp \left(-\frac{t}{a}\right) b
$$

and are called the best unbiased linear estimator. Unbiased linear estimators play an important role in application, because allow more precisely to estimate unknown parameters (Hajiyev et al., 2011). This estimator gives the least error with regard to other estimators. From the expressions (5) and (6) it follows $\bar{u}=5,6092, \bar{v}=0,1571$ and in the expression (7) and (8) $\bar{a}=273$ hours, $\bar{b}=6,36$. For the general case we have

$\bar{P}_{1}(t)=\exp \left(-\frac{t}{a}\right)^{b}=\exp \left(-\frac{t}{273}\right)^{6,36}$

Expression (9) represents non-failure operating probability of the first pumping unit. Table 4 determines the regularity of distribution of non-failure operation time for the second pumping unit.

Considering the goodness fit - criterion, we have $\boldsymbol{S}_{m}=0,53$. For the number of failures $r=11$ and accuracy level $\alpha=0,05$, from special tables, it was determined that $S_{b}=0,74$. As $S_{m} \prec S_{b}$, distribution of non-failure operation time for the second pumping unit can be approximated by the Weibull distribution.
Table 5 shows non-failure operating probability for the second pumping unit, as per Weibull distribution.

From dependence of (5) and (6) we get $\bar{u}=6,5196$ and $\bar{v}=2,1247$. From expressions (7) and (8) $\bar{a}=678$ hours, and $\bar{b}=0,47$. Similarly, for the second pumping unit, the formula (9) is

$\overline{\boldsymbol{P}}_{2}(t)=\exp \left(-\frac{t}{678}\right)^{0,47}$.

Table 5 Non-failure operating probability for the second pumping unit

\begin{tabular}{|cccc|}
\hline$t_{i}$ & $X_{i}=\operatorname{lnt}_{i}$ & $a_{i}$ & $C_{i}$ \\
\hline 275 & 5,037 & 0,016 & $-0,070$ \\
\hline 312 & 5,347 & 0,034 & $-0,074$ \\
\hline 350 & 5,375 & 0,043 & $-0,074$ \\
\hline 357 & 5,481 & 0,054 & $-0,071$ \\
\hline 396 & 5,846 & 0,066 & $-0,064$ \\
\hline 425 & 6,040 & 0,078 & $-0,054$ \\
\hline 463 & 6,047 & 0,093 & $-0,039$ \\
\hline 512 & 6,174 & 0,111 & $-0,019$ \\
\hline 514 & 6,242 & 0,133 & 0,010 \\
\hline 521 & 6,256 & 0,347 & 0,052 \\
\hline 585 & 6,372 & 0,098 & 0,402 \\
\hline
\end{tabular}


Table 6 Actual operating hours of the third pump unit

\begin{tabular}{|cccccc|}
\hline$i$ & $t_{i}$ & $X_{i}=\ln t_{i}$ & $M_{i}$ & $X_{i+1}-X_{i}$ & $\left(X_{i+1}-X_{i}\right) / M_{i}$ \\
\hline 1 & 196 & 5,2781 & 1,0484 & 0,0202 & 0,0193 \\
\hline 2 & 200 & 5,2983 & 0,5527 & 0,3001 & 0,5430 \\
\hline 3 & 270 & 5,5984 & 0,3914 & 0,087 & 0,1366 \\
\hline 4 & 273 & 5,6095 & 0,3147 & 0,043 & 0,1305 \\
\hline 5 & 285 & 5,6525 & 0,2732 & 0,0513 & 0,3178 \\
\hline 6 & 300 & 5,7038 & 0,2514 & 0,0328 & 0,0775 \\
\hline 7 & 310 & 5,7366 & 0,2439 & 0,0149 & 0,0592 \\
\hline 8 & 335 & 5,8141 & 0,2516 & 0,0682 & 0,2402 \\
\hline 9 & 340 & 5,8290 & 0,2839 & 0,2009 & 0,5277 \\
\hline 10 & 364 & 5,8972 & 6,0981 & & \\
\hline
\end{tabular}

Here, Table 6 illustrates the distribution regularity of non-failure operating time for the third pumping unit.

Based on Table 6, expressing goodness fit criterion, $S_{m} \approx 0,54$. For the numbers of failures $(r=11)$ and for the accuracy level ( $\alpha=0,05$ ) from special tables we get $S_{b}=0,74$. As $S_{m} \prec S_{b}$ and distribution of non-failure operating time for the third pumping unit can also be approximated by the Weibull distribution. Calculation of non-failure operating probability for the third pumping unit is presented in Table 7 .

Table 7 Non-failure operating probability for the third pumping unit

\begin{tabular}{|cccc|}
\hline$t_{i}$ & $X_{i}=\operatorname{lnt}_{i}$ & $\boldsymbol{a}_{i}$ & $C_{i}$ \\
\hline 196 & 5,2781 & 0,0249 & $-0,0654$ \\
\hline 200 & 5,2983 & 0,0355 & $-0,0703$ \\
\hline 270 & 5,5984 & 0,0457 & $-0,0705$ \\
\hline 273 & 5,6095 & 0,0562 & $-0,0671$ \\
\hline 285 & 5,6525 & 0,0673 & $-0,0602$ \\
\hline 300 & 5,7038 & 0,0792 & $-0,0493$ \\
\hline 310 & 5,7366 & 0,0926 & $-0,0332$ \\
\hline 335 & 5,8141 & 0,1080 & $-0,0094$ \\
\hline 340 & 5,8290 & 0,1271 & 0,0269 \\
\hline 364 & 5,8972 & 0,1532 & 0,0891 \\
\hline 445 & 6,0981 & 0,2104 & 0,3094 \\
\hline
\end{tabular}

$\bar{P}_{3}(t)=\exp \left(-\frac{t}{334}\right)^{4,84}$

Reliability and failure probability of the pumping station were calculated according to Hajiyev \& Shahbazov (2000) and as follows

$$
\bar{P}_{n / s t}=\prod_{i=1}^{4} \bar{P}_{i}, \quad q \approx 1-P_{n / s t}(t) .
$$

In the case of a reserved pumping unit it is calculated as

$$
\begin{gathered}
\bar{P}_{n / s t}=\sum_{i=0}^{N-n} C_{N}^{i}\left(1-P_{0}\right)^{i} \cdot P_{0}^{N-1}, \\
q_{n, N}=C_{N}^{n} P_{0}^{N-n}\left(1-P_{0}\right)^{n}
\end{gathered}
$$

It was assumed that the system has a structural design and a constant resource(Figure 1)

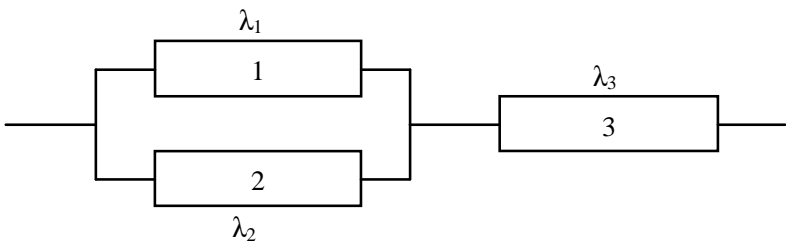


Figure 1 Reliability of block-design of the pumping station.

The system's reliability is calculated by the following expression:

$$
P_{S}(t)=\left[1-\left(1-e^{-(t / 273)^{6,36}}\right) \cdot\left(1-e^{-(t / 678)^{0,47}}\right)\right] \cdot e^{-(t / 334)^{4,84}}
$$

If we assess the functions on the interval $0 \div 300$ by 25 hour steps, we get the following Table 8 .

Table 8 System's reliability on the interval $0 \div 300$ by 25 hour steps

\begin{tabular}{|ccccc|}
\hline$t_{i}$ & $P_{1}(t)$ & $P_{2}(t)$ & $P_{3}(t)$ & $P_{n / s t}(t)$ \\
\hline 0 & 1 & 1 & 1 & 1 \\
\hline 25 & 0,999 & 0,81 & 0,999 & 0,9999 \\
\hline 50 & 0,999 & 0,75 & 0,999 & 0,9998 \\
\hline 75 & 0,999 & 0,70 & 0,999 & 0,9991 \\
\hline 100 & 0,998 & 0,67 & 0,997 & 0,9965 \\
\hline 125 & 0,993 & 0,64 & 0,991 & 0,9889 \\
\hline 150 & 0,978 & 0,61 & 0,979 & 0,9710 \\
\hline 175 & 0,94 & 0,59 & 0,957 & 0,9345 \\
\hline 200 & 0,87 & 0,57 & 0,920 & 0,8686 \\
\hline 225 & 0,75 & 0,55 & 0,86 & 0,7645 \\
\hline 250 & 0,57 & 0,54 & 0,78 & 0,6235 \\
\hline 275 & 0,35 & 0,52 & 0,68 & 0,4658 \\
\hline 300 & 0,16 & 0,51 & 0,55 & 0,3231 \\
\hline
\end{tabular}

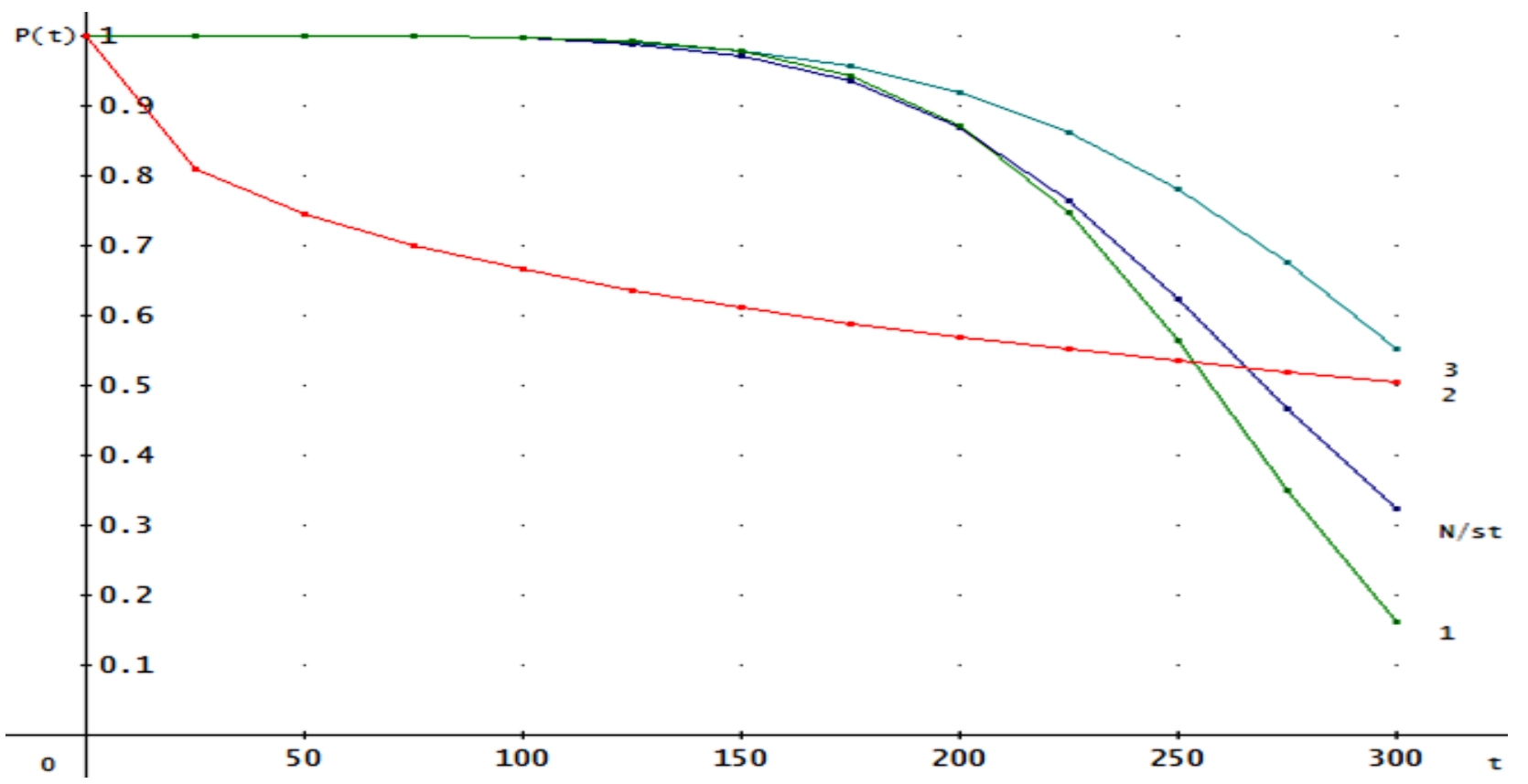

Figure 2 Probabilities of continuous operation of 1, 2 and 3 pumping units and pumping stations.

Journal of Experimental Biology and Agriculture Science http://www.jebas.org
Integrating the expression (14) i.e. probability of continuous operation system for the pumping station, during a time interval

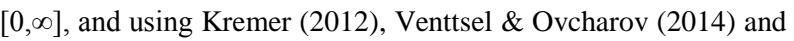
Hajiyev \& Rustamov (2015), the mean value of continuous operating time for the system was equal to

$T=\int_{0}^{\infty}\left[1-\left(1-e^{-(t / 273)^{6,36}}\right) \cdot\left(1-e^{-(t / 678)^{0.47}}\right)\right] \cdot e^{-(t / 334)^{4,84}} d t=273$

The probability of continuous operation of pumping units and the pumping station are expressed in the form of curves (Figure 2). The number of curves corresponds to numbers of pumping units. $\mathrm{N} / \mathrm{st}$ describes the behavior for the probability of continuous operation system.

It follows from behavior of the curves, that the probability of continuous operation system, in the case of the Weibull distribution, gets large values in small domains, and small values at large values of $t$.

Therefore, systems failure probability, density distribution and failure intensity of continuous operation time can be calculated as

$$
\begin{gathered}
Q_{S}=\left(1-e^{-(t / 273)^{6.36}}\right) \cdot\left(1-e^{-(t / 678)^{0.47}}\right) \cdot\left(1-e^{-(t / 334)^{4,84}}\right) \\
f_{S}(t)=\frac{\partial}{\partial t}\left(\left(1-e^{-(t / 273)^{6.36}}\right) \cdot\left(1-e^{-(t / 678)^{0.47}}\right) \cdot\left(1-e^{-(t / 334)^{4.84}}\right)\right)
\end{gathered}
$$

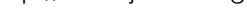


$\lambda_{S}(t)=\frac{\frac{\partial}{\partial t}\left(\left(1-e^{-(t / 273)^{6.36}}\right) \cdot\left(1-e^{-(t / 678)^{0.47}}\right) \cdot\left(1-e^{-(t / 334)^{4.34}}\right)\right)}{\left[1-\left(1-e^{-(t / 273)^{6.36}}\right) \cdot\left(1-e^{-(t / 678)^{0.47}}\right)\right] \cdot e^{-(t / 334)^{4.84}}}$

The appropriate curves (Figure $3 \& 4$ ) were plotted using expression (17) and (18).

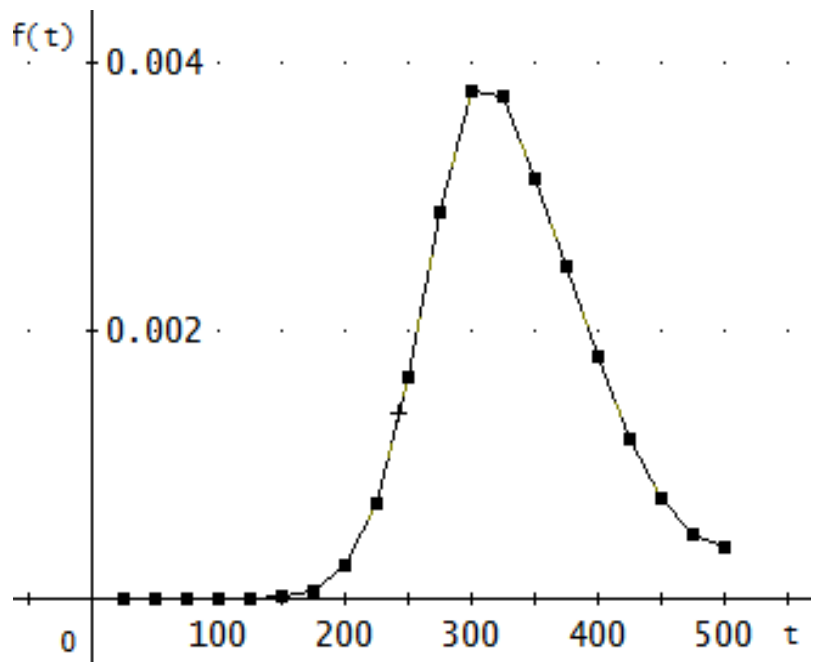

Figure 3. Density of distribution of time time to failure

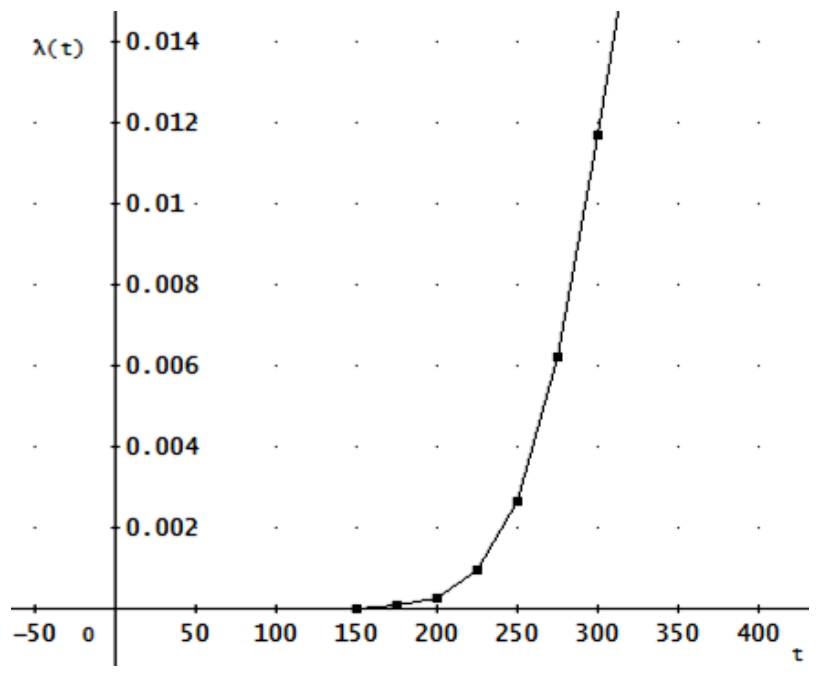

Figure 4. Intensity of distribution of to failure

For different values of $t$, under expressions (11), (12), (13) and (14), the reliability of pumping units at a perticular station was calculated by using the formula (15) and (16).

\section{Conclusions}

The "Shimal-2" pumping station of district Salyan, Azerbaijan was designed without considering the reliability conditions. In such cases, the engineering equipment does not satisfy the reliability requirements, thereafter, the possibility of failures is there with increased exploitation cost. As a result, continuous operating period decreases and the equipment fails before the end of the exploitation period or without operation efficiency. In the paper, the service of the pumping station used for meliorative purposes and an amount of water required for injection are not reached, because according to operating hours, every unit does not work at its total power, but with intervals. Under two pumpsystem,one unit is always in reserve, therefore, the system fulfils its function i.e., the pumping station has a permanently installed resource unit. According to theoretical results and graphical description, "Shimal-2" pumping station has although been exploited for a long period, however, it was determined that this station works according to the reliability requirements. Additionally, the system was achived through a permanently installed resource. In this paper, for determining the system's reliability, all three cases were considered.

\section{Acknowledgements}

This work was supported by the Science Development Foundation under the President of the Republic of Azerbaijan, Grant № EIFKETPL-2-2015-1(25)-56/13/1. The authors express their deep appreciation to the Development Foundation for the financial support.

Special thanks to Prof. Mirza Barjees Baig for his kind invitation to contribute in the special issue of the journal of Experimental Biology and Agricultural Sciences.

\section{References}

Ahmadova HY, Allahverdiyev DE, Hajiyev AH (2010) Enciclopedia Encyclopedia. Theory of Probability and Mathematical Statistics. Baku, Elm, Pp. 1083.

Ahmedzade AS, Hashimov AS (2016) Ensyclopedia on melioration. Baku, Radius, Pp.632 (in Azerb.)

Barlou R, Proshan F (1984) Statistical Theory of Reliability and Reliability Testing, Nauka, Moscow.

Belyaev YK (1976) Lectures in Reliability Theory. Polytechnical Muzeum., M.

Gnedenko BV, Belyaev YK, Solovyov AD (2013) Mathematical methods in the theory of reliability. M.: LIBROKOM, Pp. 584. 
Hajiyev AH (2011) Regression Models with Increasing Numbers of Unknown Parameters. In: International Encyclopedia. Statistical Sciences, Springer, Pp.1208-1211.

Hajiyev AH, Rustamov YI (2015) On a distribution function and reliability parameters of busy period for pump stations during continuos operation. World Journal of Modelling and Simulation $\mathrm{X}(\mathrm{XXXX}): 3-10$

Hajiyev AH, Shahbazov E (2000) Statistical problems of reliability in a projecting of oil pipeline. Book: Reliability-2000, Beardoux, France, Pp. 33-35.

Kapur K, Lamberson L (1980) Reliability and design of systems. M.: Mir, Pp.604

Kremer NS (2012) Theory of Probability and Mathematical Statistics. M.: UNITI DANA, Pp. 512.

Lehmann EL (1959) Testing of Statistical Hypothesis.
Mann R, Fertig K, Scheuer E (1971) Tolerance Bounds and a New Goodness of Fit for Two-Parameter Weibull or ExtremeValue Distribution, Aerospace Research Laboratories.

Polovko AM, Gurov SV (2008) Bases of the theory of reliability. St. Petersburg: Petersburg, Pp. 702.

Rustamov YI (2010) Assessment of reliability of land-reclamation pump stations// Investia Agrarnoy nauki, vol. 8, № 2, Pp. 69-72.

Rustamov YI (2013) Reliability conditions and reasons of failures in pump stations// Azerbaijan Agrar Elmi, № 3, Pp. 111-114. (in Azerb.)

State Standards 27. 003-90. (1990) Structure and general rules on reliability requirements. M.: Gos. Standart SSSR, Pp.20.

Venttsel ES, Ovcharov LA (2014) Tasks and exercises on probability theory. M.: KNORUS, 2: 496. 